\title{
ANALISIS STRUCTURAL EQUATION MODELING (SEM) FAKTOR-FAKTOR YANG MEMENGARUHI PERILAKU BULLYING REMAJA AWAL DI DENPASAR
}

\author{
Gusti Ayu Rusma Windiyana Putri, Ni Made Dian Kurniasari, I Ketut Tangking Widarsa \\ Program Studi Sarjana Kesehatan Masyarakat, Fakultas Kedokteran, Universitas Udayana \\ Alamat: Jalan PB. Sudirman, Denpasar, Bali 80232
}

\begin{abstract}
ABSTRAK
Bullying merupakan perilaku negatif yang dapat menyebabkan masalah kesehatan mental. Penelitian ini bertujuan untuk mengetahui faktor-faktor yang memengaruhi perilaku bullying remaja awal di Denpasar. Jenis penelitian ini adalah analitik kuantitatif dengan desain cross-sectional. Sampel penelitian ini yaitu siswa dan siswi kelas VII dan VIII sejumlah 279, dipilih dengan multistage random sampling. Data yang dikumpulkan adalah karakteristik responden, perilaku bullying, pengetahuan, sikap, konsep diri, stress akademik, situasi keluarga, konformitas teman sebaya, iklim sekolah, dan media menggunakan kuesioner dalam jaringan (daring) kobotoolbox. Data dianalisis menggunakan metode SEM. Hasil penelitian menunjukan bahwa prevalensi perilaku bullying remaja awal di Denpasar adalah 83,15\% dengan kategori rendah. Bullying verbal paling sering dilakukan remaja awal dengan kategori rendah (71,68\%) dan kategori tinggi (1,43\%). Bullying psikologis dilakukan remaja awal dengan kategori rendah (46,95\%) dan bullying fisik dengan kategori rendah (44,09\%). Faktor yang signifikan memengaruhi perilaku bullying adalah situasi keluarga (total efek= $-0,20$ ), konformitas teman sebaya (total efek=0,17), iklim sekolah (total efek= -0,18), dan media (total efek=2,14). Perilaku bullying remaja awal di Kota Denpasar masih relatif tinggi, perlu adanya dukungan dari berbagai sektor untuk dapat mengontrol perilaku dan menurunkan prevalensi perilaku bullying.
\end{abstract}

Kata Kunci: Bullying, Faktor Bullying, Remaja Awal, SEM

\begin{abstract}
Bullying is a negative behavior that can cause mental health problems. This study aims to determine the factors that affecting the bullying behavior of young adolescents in Denpasar City. This is quantitative analytic research with cross-sectional design. The sample of this research is students of class VII and VIII, 279 young adolescents were selected by multistage random sampling. Data collected were respondents' characteristics, bullying behavior, knowledge, attitudes, self-concept, academic stress, family situations, peer conformity, school climate, and the media using an online questionnaire kobotoolbox. The results showed that the prevalence of bullying behavior young adolescents in Denpasar is $83,15 \%$ with low category. Verbal bullying was highest in low category $(71.68 \%)$ and high category $(1.43 \%)$ followed by psychological bullying in low category $(46.95 \%)$ and physical bullying in low category (44.09\%). Significant factors influencing young adolescent bullying behavior are family situation (total effect $=-0,20$ ), peer conformity (total effect $=0.17$ ), school climate (total effect $=-0.18$ ), and media (total effect $=2.14$ ). Bullying behavior of young adolescents in Denpasar City is still relatively high, support from various sectors is required to control behavior and reduce the prevalence of bullying behavior.
\end{abstract}

Key Words: Bullying, Bullying Factors, Young Adolescent, SEM

\section{PENDAHULUAN}

Bullying saat ini merupakan masalah yang menjadi perhatian dunia. Bullying atau perundungan berasal dari kata "rundung" yang berarti mengganggu, mengusik terus-menerus, dan menyusahkan. Tujuan dari perilaku bullying adalah mendominasi, menyakiti, dan mengasingkan pihak lain, karena tindakan negatif ini bisa dilakukan oleh individu maupun kelompok (Putri, 2015). Bullying diklasifikasikan menjadi bentuk fisik, verbal, dan psikologis (Coloroso, 2007). Penelitian yang dilakukan pada tahun 2017 mendapatkan hasil bahwa bullying verbal paling banyak terjadi yaitu sebesar $47 \%$, diikuti oleh bullying fisik (30\%) dan bullying sosial/ psikologis (20\%) (Marela et al., 2017).

Bullying berdampak pada kesehatan mental dari pelaku, korban, dan orang sekitarnya. Hasil penelitian dari Finlandia menyebutkan dari 16.410 remaja, 1.423 
siswa diklasisifikasikan mengalami depresi tingkat sedang hingga berat penyebab salah satunya adalah bullying (Hasan, 2013). Hasil survey Program for International Student Assessment (PISA) tahun 2018 menyatakan $41 \%$ siswa di Indonesia pernah mengalami perlakuan bullying, persentase ini menjadikan Indonesia menempati kedudukan tertinggi ke-5 di dunia (Schleicher, 2019). Komisi Perlindungan Anak Indonesia (KPAI) mencatat dari tahun 2011 hingga 2014 pengaduan terkait bullying sejumlah 369 kasus (25\%) dari 1.480 kasus total pengaduan di bidang pendidikan (Kundre, 2018) dan paling banyak dilakukan oleh teman sekelas $(42,1 \%)$. Data dari Yayasan Semai Jiwa Amini (SEJIWA) mendapatkan kekerasan sesama siswa di tingkat SMP sebanyak 41,2\% dengan kategori tertinggi yaitu pengucilan, diikuti dengan kekerasan verbal dan kekerasan fisik (Wardani, 2017). Penelitian oleh Windasari (2015) mendapatkan data bahwa dari 160 pelajar SMP di Kota Denpasar yang mengikuti penelitian, prevalensi bullying adalah 74 $(46,25 \%) \quad$ siswa. Santrock mendefinisikan masa remaja adalah masa labil karena masa ini adalah masa transisi dari anak ke dewasa, sehingga terjadi perubahan dari segi biologis, kognitif dan sosioemosional yang dapat memicu terjadinya bullying. Pengelompokan masa remaja yang pertama adalah masa remaja awal. Remaja awal adalah individu pada rentang umur 12-16 tahun, belum menikah atau pada usia ini duduk pada jenjang SMP (Depkes RI, 2009).

Perilaku bullying cenderung dianggap sebagai hal yang biasa, padahal bullying dapat memberikan dampak yang cukup serius. Pada tahun 2015, 71\% dari $84 \%$ siswa yang mengalami kekerasan di sekolah beranggapan bahwa perilaku bullying merupakan hal yang lumrah (Tanlain, 2017). Dampak negatif yang ditimbulkan berbeda tergantung dengan tingkat keparahannya. Bagi korban, bully akan menjadikan remaja tersebut merasa takut dan terintimidasi. Pelaku bullying cenderung akan memiliki tingkat agresifitas, kemarahan, dan depresi yang tinggi, tidak punya rasa empati, dan terindikasi terlibat dalam perilaku kriminal (Ahmad, 2019).

Kajian dari beberapa literatur, faktor penyebab bullying sangat beragam. Peneliti menggunakan Teori Ecological Model of Health Behavior oleh Kenneth McLeroy (1988) sebagai dasar untuk mencari faktor-faktor yang berpengaruh terhadap bullying. Teori tersebut menyatakan bahwa perilaku manusia dipengaruhi oleh faktor-faktor yang bertingkat. Faktor pertama adalah faktor intrapersonal, yaitu faktor yang ada pada diri individu itu sendiri, seperti pengetahuan, sikap, konsep diri, dan stress akademik. Faktor di tingkat kedua adalah faktor interpersonal dan grup utama, jaringan sosial formal dan informal dan sistem dukungan sosial, termasuk keluarga, rekan kerja, dan teman sebaya. Faktor ketiga adalah faktor institusional, yaitu organisasi formal dan informal yang memiliki peraturan baku, contohnya lingkungan/ iklim sekolah. Faktor keempat adalah faktor komunitas, yaitu komunitas yang dapat 
memengaruhi perilaku, misalnya paparan media.

Faktor pertama adalah pengetahuan dan sikap mengenai perilaku bullying. Kedua faktor ini adalah faktor dasar pembentuk perilaku manusia (Nurhayanti et al., 2013). Faktor selanjutnya yang memengaruhi bullying adalah konsep diri. Konsep diri negatif berarti cara pandang seseorang terhadap dirinya sendiri rendah, merasa tidak berharga, dan memicu perilaku yang negatif. Sedangkan konsep diri positif adalah orang yang mampu menerima diri apa adanya dan cenderung berperilaku positif (Lestari, 2018; Usman, 2013; Yandri, 2014). Iklim sekolah dan stress akademik juga sangat menentukan kecenderungan adanya kasus bullying di suatu sekolah (Usman, 2013; Utami, 2019). Lingkungan belajar, fisik, sosial, keamanan sekolah, serta hubungan interpersonal guru dan siswa yang baik akan menciptakan suasana atau iklim sekolah yang baik (Azeredo et al., 2015; Putri et al., 2015). Lingkungan terdekat, yaitu situasi keluarga dan konformitas teman sebaya dapat memengaruhi perilaku karena remaja awal cenderung meniru dan beradaptasi dengan ada di sekitarnya (Tumon, 2014; Zakiyah et al., 2017). Remaja awal saat ini sudah sangat dekat dengan media, baik itu media masa dan media elektronik. Media juga berpotensi untuk memengaruhi perilaku (Sari et al., 2017).

Faktor-faktor yang memengaruhi bullying tersebut sangat kompleks, sehingga tidak cukup bila dianalisis dengan metode yang sederhana. Penelitianpenelitian sebelumnya hanya menggunakan analisis regresi yang melihat hubungan linier. Faktor-faktor tersebut bisa saja saling berhubungan satu dengan yang lain. Analisis SEM merupakan metode yang dapat menganalisis hubungan kompleks tersebut. Kelebihan SEM dibandingkan dengan analisis data yang lain adalah dapat digunakan untuk membuat model untuk mengetahui indikator pembentuk suatu variabel, menguji validitas dan reliabilitas suatu instrumen, mengkonfirmasi ketepatan model dan menguji pengaruh suatu variabel terhadap variabel lain.

Penelitian serupa dilakukan oleh Tanlain (2017). Penelitian ini berjudul "Pemodelan Faktor-Faktor yang Mempengaruhi Perilaku Bullying Siswa SMA "X" Surabaya dengan Metode Structural Equation Modeling". Perbedaan dengan penelitian yang peneliti saat ini lakukan adalah, penelitian tersebut dilakukan di Surabaya, sedangkan penelitian ini di Bali. Sampel pada penelitian Tanlain (2017) merupakan anak SMA, dan variabel yang diukur hanya dari peran keluarga, keadaan kepribadian, dan stress. Faktor yang sangat memengaruhi perilaku bullying dalam penelitian tersebut adalah faktor stres.

Berdasarkan latar belakang di atas, peneliti ingin membuat suatu model untuk mengetahui bagaimana faktor-faktor tersebut berpengaruh terhadap perilaku bullying di kalangan remaja awal (siswa SMP) di Kota Denpasar dengan menggunakan analisis SEM.

\section{METODE PENELITIAN}

Jenis penelitian ini adalah analitik kuantitatif dan desain yang digunakan adalah cross-sectional. Populasi target 
dalam penelitian ini adalah seluruh remaja awal (12-16 tahun) di Kota Denpasar dan populasi terjangkau adalah siswa kelas VII dan VIII di SMP Negeri dan SMP Swasta yang terpilih di Kota Denpasar. Sumber data adalah data primer dengan variabel yang diteliti yaitu karakteristik responden (umur, jenis kelamin, jenis sekolah, kelas), perilaku bullying (verbal, fisik, psikologis), dan faktor-faktor yang memengaruhinya (pengetahuan, sikap, konsep diri, stress akademik, situasi keluarga, konformitas teman sebaya, iklim sekolah, media). Hasil ukur masing-masing variabel adalah skor. Selain skor, untuk perilaku bullying juga dikategorikan menjadi tidak pernah (skor $0)$, rendah (skor 1-20), tinggi (skor 21-40). Kategori masing-masing jenis bullying juga dibagi menjadi tidak pernah, rendah, dan tinggi sesuai dengan skor yang diperoleh. Besar sampel minimal adalah 144 diperoleh menggunakan rumus pengukuran sampel SEM. Dalam upaya meminimalisir missing data dan agar mendapat model yang baik dari indikator yang diukur banyak, peneliti menggunakan seluruh responden (279 responden) yang mengisi kuesioner di sekolah dan kelas yang terpilih.

Berkaitan dengan adanya pandemi Covid-19, pengumpulan data dilakukan dengan menyebarkan kuesioner online kepada responden. Peneliti mencari kontak sekolah melalui website dan masuk ke grup kelas yang terpilih menjadi sampel. Analisis data menggunakan analisis SEM dimulai dari univariat, uji asumsi dan persyaratan, CFA, dan analisis jalur. Penelitian ini telah dinyatakan laik etik oleh Komisi Etik Penelitian Litbang FK Unud/RSUP Sanglah dengan nomor 1140/UN14.2.2.VII.14/LT/2020.

\section{HASIL}

Karakteristik remaja awal disajikan pada tabel 1, menunjukan sebanyak $54,48 \%$ remaja berasal dari sekolah negeri. Ratarata usia 13,5 tahun dan memiliki standar deviasi 0,68. Remaja laki-laki dan perempuan cukup merata pada analisis ini dengan proporsi remaja laki-laki 50,54\%.

Tabel 1. Karakteristik dan Ringkasan Statistik Remaja Awal (n=279)

\begin{tabular}{lc}
\hline \multicolumn{1}{c}{ Karakteristik } & Ringkasan Statistik \\
\hline Umur & $13,5(0,68)$ \\
$\quad$ Mean (SD) & \\
Sekolah (n, \%) & $152(54,48)$ \\
Negeri & $127(45,52)$ \\
Swasta & \\
Jenis Kelamin (n, \%) & $141(50,54)$ \\
Laki-laki & $138(49,46)$ \\
Perempuan & \\
\hline
\end{tabular}


Tabel 2. Prevalensi Perilaku Bullying Remaja Awal di Denpasar ( $\mathrm{n}=279)$

\section{Bullying}

\section{Perilaku Bullying}

Tidak pernah

Rendah

\section{Bullying Verbal}

Tidak pernah

Jumlah n (\%)

Rendah

Tinggi

Bullying Fisik

Tidak pernah

Rendah

\section{Bullying Psikologis}

Tidak pernah

Rendah
$47(16,85)$

$232(83,15)$

$75(26,88)$

$200(71,68)$

$4(1,43)$

$156(55,91)$

$123(44,09)$

$148(53,05)$

$131(46,95)$

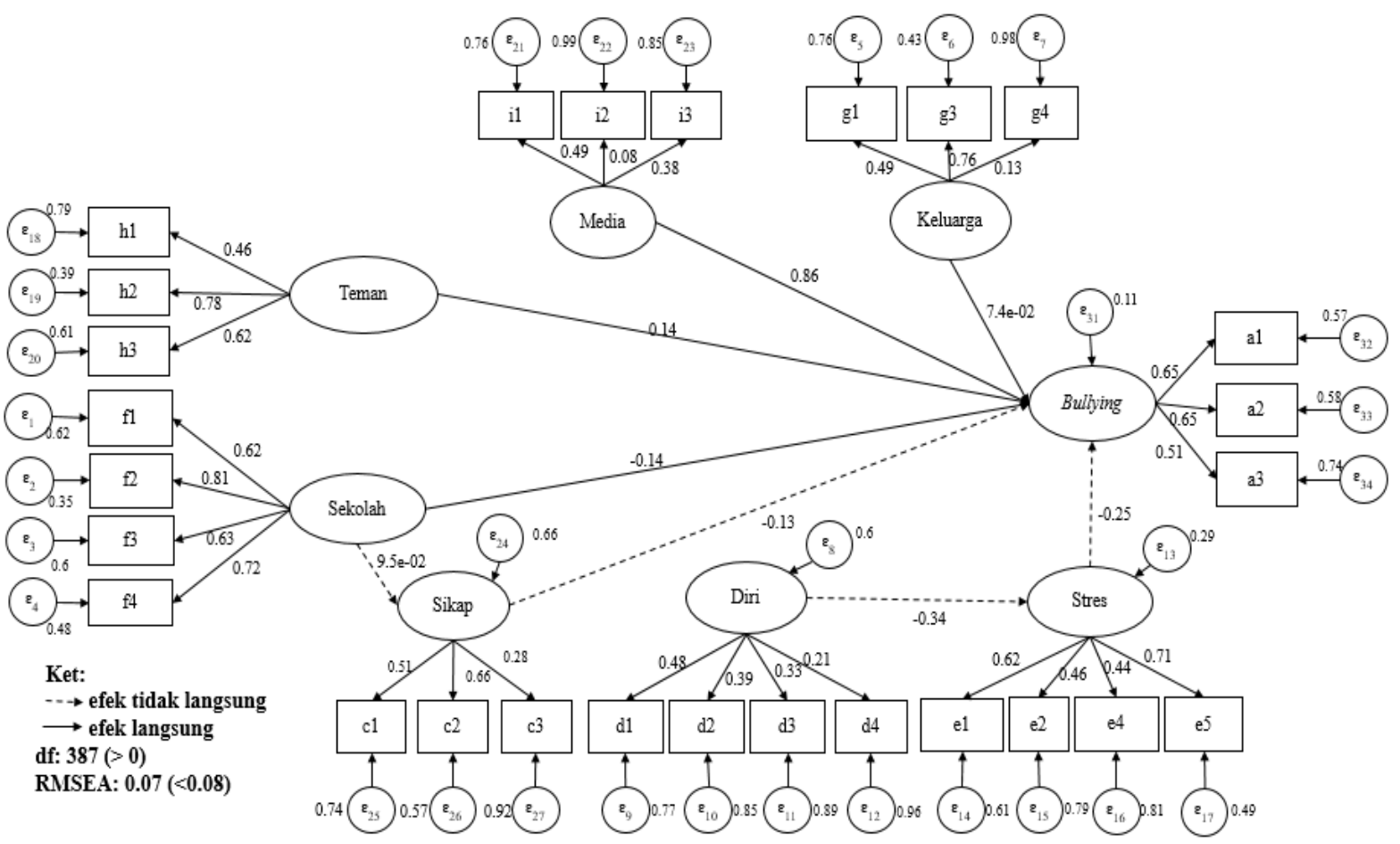

Gambar 1. Model Analisis Faktor-Faktor yang Memengaruhi Perilaku Bullying

Tabel 3. Faktor-Faktor yang Memengaruhi Perilaku Bullying $(\mathrm{n}=\mathbf{2 7 9 )}$

\begin{tabular}{lcccc}
\multicolumn{1}{r}{ Faktor Pengaruh } & Koefisien & $\mathbf{9 5 \%}$ CI & S.E \\
\hline Sikap & & & & \\
Efek Langsung & $-0,28$ & $-1,15$ & 0,58 & 0,44 \\
Total & $\mathbf{- 0 , 2 8}$ & $-1,15$ & 0,58 & 0,44
\end{tabular}

Stres Akademik 


\begin{tabular}{|c|c|c|c|c|}
\hline \multirow{2}{*}{$\begin{array}{l}\text { Faktor Pengaruh } \\
\text { Efek Langsung }\end{array}$} & \multirow{2}{*}{$\begin{array}{c}\text { Koefisien } \\
-0,26\end{array}$} & \multicolumn{2}{|c|}{$95 \% \mathrm{CI}$} & \multirow{2}{*}{$\frac{\text { S.E }}{0,44}$} \\
\hline & & $-1,12$ & 0,60 & \\
\hline Total & $-0,26$ & $-1,12$ & 0,60 & 0,44 \\
\hline \multicolumn{5}{|l|}{ Pengetahuan } \\
\hline Efek Langsung & 0,24 & $-0,62$ & 1,11 & 0,44 \\
\hline Efek Tidak Langsung (Sikap) & 0,16 & $-0,34$ & 0,66 & 0,25 \\
\hline Total & 0,40 & $-0,29$ & 1.10 & 0,35 \\
\hline \multicolumn{5}{|l|}{ Konsep Diri } \\
\hline Efek Langsung & $-0,98$ & $-2,70$ & 0,74 & 0,88 \\
\hline Efek Tidak Langsung (Stres akademik) & $0,34^{*}$ & 0,16 & 0,52 & 0,09 \\
\hline Total & $-0,64$ & $-2,26$ & 0,98 & 0,82 \\
\hline \multicolumn{5}{|l|}{ Media } \\
\hline Efek Langsung & $2,21^{*}$ & 0,66 & 3,77 & 0,79 \\
\hline Efek Tidak Langsung (Sikap) & $-0,07$ & $-0,39$ & 0,23 & 0,16 \\
\hline Total & $2,14^{*}$ & 0,74 & 3,55 & 0,71 \\
\hline \multicolumn{5}{|l|}{ Iklim Sekolah } \\
\hline Efek Langsung & $-0,17$ & $-0,38$ & 0,04 & 0,11 \\
\hline Efek Tidak Langsung (Sikap) & $-0,01$ & $-0,06$ & 0,04 & 0,03 \\
\hline Total & $-0,18$ & $-0,38$ & 0,02 & 0,10 \\
\hline \multicolumn{5}{|l|}{ Situasi Keluarga } \\
\hline Efek Langsung & 0,11 & $-0,38$ & 0,60 & 0,25 \\
\hline $\begin{array}{l}\text { Efek Tidak Langsung (Konsep diri, } \\
\text { sikap) }\end{array}$ & $-0,31$ & $-0,71$ & 0,09 & 0,20 \\
\hline Total & $-0,20$ & $-0,51$ & 0,10 & 0,16 \\
\hline \multicolumn{5}{|l|}{ Konformitas Teman Sebaya } \\
\hline Efek Langsung & 0,24 & $-0,17$ & 0,66 & 0,21 \\
\hline Efek Tidak Langsung (Sikap) & $-0,07$ & $-0,29$ & 0,14 & 0,11 \\
\hline Total & 0,17 & $-0,17$ & 0,51 & 0,17 \\
\hline
\end{tabular}

${ }^{*} \mathrm{p}<0,05$ = signifikan secara statistik

Hasil analisis tabel 2 menunjukan prevalensi perilaku bullying secara umum terdapat 232 responden (83,15\%) melakukan perilaku bullying dengan kategori ringan. Perilaku bullying verbal menjadi jenis bullying yang paling banyak dilakukan dengan kategori rendah 71,68\% dan kategori tinggi 1,43\%. Jenis bullying psikologis dilakukan oleh responden dengan kategori rendah sebanyak 46,95\%, dan perilaku bullying fisik paling sedikit dilakukan oleh responden (44,09\%). Gambar 1 menunjukan model faktor-faktor yang memengaruhi bullying secara langsung dan tidak langsung, yang secara rinci dibuat pada tabel 3. Berdasarkan tabel 3, faktor komunitas, yaitu media signifikan memengaruhi bullying dengan total efek 2,14. Peneliti mempertimbangkan adanya pengaruh faktor walaupun terlihat kecil dari nilai CI dan $\mathrm{p}$ value yang didapat, dimana faktor 
institusional, yaitu iklim sekolah memengaruhi perilaku bullying dengan total efek -0,18. Faktor interpersonal situasi keluarga dan konformitas teman sebaya memengaruhi perilaku bullying dengan total efek -0,20 dan 0,17. Hasil pengukuran menunjukan faktor intrapersonal tidak memengaruhi perilaku bullying. Faktor yang signifikan langsung memengaruhi bullying adalah media dengan efek 2,21 dan iklim sekolah $(-0,17)$ dengan mempertimbangkan nilai $\mathrm{CI}$ dan $p$ value. Faktor konsep diri memengaruhi signifikan perilaku bullying secara tidak langsung melalui stres akademik dengan efek 0,34. Peneliti mempertimbangkan adanya pengaruh faktor walaupun terlihat kecil dari nilai CI dan $p$ value yang didapat, dimana faktor iklim sekolah memengaruhi perilaku bullying secara tidak langsung melalui sikap dengan efek -0,01.

\section{DISKUSI}

Perilaku bullying secara umum dan jenis-jenis bullying masing-masing dikategorikan berdasarkan skor yang diperoleh, dibagi menjadi tidak pernah, rendah, dan tinggi. Prevalensi bullying responden secara umum sebanyak 232 (83,15\%) melakukan perilaku bullying. Bullying verbal menjadi jenis bullying yang paling sering dilakukan responden dengan kategori rendah $(71,68 \%)$ dan kategori tinggi $(1,43 \%)$. Jenis bullying psikologis dilakukan oleh responden dengan kategori rendah sebanyak $46,95 \%$, dan perilaku bullying fisik paling sedikit dilakukan oleh responden dengan kategori rendah (44,09\%). Hasil ini sejalan dengan penelitian Hermalinda et al. (2017) yang mendapatkan bullying verbal paling banyak dilakukan oleh remaja (42,4\%) diikuti dengan bullying fisik dan bullying psikologis. Penelitian ini juga sejalan dengan Windasari (2015) yang dilakukan di Denpasar. Kejadian bullying didominasi oleh bullying verbal, diikuti dengan bullying psikologis dan bullying fisik. Perilaku bullying di area sekolah sudah dianggap hal yang wajar dan dianggap hanya bercanda atau bergurau (Susanti \& Wulanyani, 2019). Responden juga cenderung menganggap bahwa bullying verbal tidak memiliki konsekuensi yang begitu serius dibandingkan dengan bullying fisik maupun psikologis, padahal ketiga jenis bullying ini memiliki konsekuensi yang sama (Susanti, 2019; Tumon, 2014). Moral remaja sudah rendah dan menyebabkan ia memandang perlakuan bullying fisik pantas dilakukan kepada korbannya dan menganggap itu hanya bercanda (Nadhifa, 2018). Salah satu ciri perilaku bullying adalah dilakukan oleh pihak yang lebih kuat ke pihak yang lemah (Coloroso, 2007). Penelitian Trevi \& Respati (2012) mendapat hasil remaja masih suka melakukan bullying psikologis karena merasa dirinya lebih kuat dari remaja lainnya.

Pengetahuan pada penelitian ini tidak signifikan memengaruhi bullying dengan efek langsung 0,24, efek tidak langsung melalui sikap 0,16 dan total efek 0,40 . Hasil penelitian ini sejalan dengan penelitian Pouwels et al. (2017) yang menemukan bahwa pengetahuan seorang individu terhadap bullying tidak menjamin perilaku individu terhadap bullying. Hal ini tidak sejalan dengan penelitian 
Kholilah (2012) yang mendapatkan hasil pengetahuan memiliki hubungan dengan bullying $(p=0,001)$ dimana semakin baik pengetahuan remaja terkait bullying maka semakin rendah perilaku bullying-nya. Perbedaan hasil ini terjadi karena perbedaan lokasi dan karakteristik responden.

Faktor sikap tidak signifikan memengaruhi perilaku bullying dengan efek langsung sebesar -0,28 dan total efek 0,28 . Hal ini tidak sejalan dengan penelitian Trevi \& Respati (2012) yang mendapatkan hubungan bahwa sikap remaja yang setuju terhadap perilaku bullying menyebabkan kecenderungan remaja menjadi pelaku bullying. Perbedaan ini terjadi dikarenakan perbedaan lokasi, karakteristik responden, dan indikator sikap yang diukur. Tidak adanya pengaruh pengetahuan dan sikap dengan bullying dapat dikarenakan adanya kontradiksi. Pengetahuan dan sikap responden sudah baik, namun perilaku bullying masih tinggi.

Aspek yang diukur pada faktor konsep diri dibagi menjadi konsep diri akademik, konsep diri sosial, konsep diri emosional, dan konsep diri fisik. Hasil analisis pengukuran faktor konsep diri tidak berpengaruh terhadap bullying dengan efek langsung -0,98, efek tidak langsung melalui stress akademik 0,34 dan total efek sebesar -0,64. Hal ini tidak sejalan dengan Lestari (2018) yang mendapatkan hasil bahwa konsep diri memiliki hubungan negatif signifikan dengan bullying. Perbedaan hasil ini terjadi karena perbedaan lokasi dan karakteristik responden.

Hasil analisis stress akademik menunjukan tidak signifikan memengaruhi bullying dengan efek langsung dan total efek sebesar -0,26. Aspek yang diukur adalah tekanan kegiatan belajar, beban tugas, kekhawatiran terhadap nilai, harapan terhadap diri sendiri, dan keputusasaan berdasarkan instrumen Educational Stress Scale for Adolescent (ESSA) (Sun, 2011). Hasil ini tidak sejalan dengan penelitian Leung \& To (2009) yang mendapatkan pengaruh signifikan stress akademik terhadap bullying. Perbedaan ini terjadi karena perbedaan lokasi, responden dan perbedaan tuntutan akademis tempat penelitian. Barseli et al. (2017) menyebutkan bahwa stress akademik bersumber dari tekanan dan tuntutan di bidang akademik. Sesuai dengan penelitian Tamtomo (2014), stress akademik yang tinggi dapat memicu perilaku bullying.

Situasi keluarga signifikan memengaruhi perilaku bullying dengan efek langsung sebesar 0,11, efek tidak langsung melalui konsep diri sebesar $-0,31$ dan total efek sebesar -0,20. Zakiyah et al. (2017) menyebutkan bahwa pelaku bullying sering berasal dari keluarga yang bermasalah. Anak yang terbiasa melihat konflik dan kekerasan dalam keluarga kemudian akan meniru tindakan tersebut kepada teman-temannya. Perlakuan bullying oleh saudara kandung masih terjadi. Hal ini karena ketidakseimbangan kekuatan antar saudara kandung yang kemudian ditiru karena merasa hal tersebut normal terjadi di keluarganya begitu pula jika ia melakukan kepada temannya (Borualogo \& Gumilang, 2019).

$$
\text { Hasil analisis menunjukan }
$$

konformitas teman sebaya signifikan memengaruhi bullying dengan efek langsung sebesar 0,24, efek tidak langsung 
melalui sikap sebesar - 0,07, dan efek total 0,17 . Semakin tinggi konformitas teman sebaya atau ketergantungan terhadap kelompok, maka semakin tinggi pula perilaku bullying remaja awal tersebut. Hasil ini sejalan dengan penelitian Lestari (2018) yang mendapatkan pengaruh positif signifikan antara konformitas teman sebaya dengan perilaku bullying. Sumbangan efektif konformitas teman sebaya terhadap bullying adalah sebesar 21,5\% (Dewi, 2015). Remaja awal yang memiliki konformitas tinggi terhadap teman sebaya akan melakukan apapun agar diterima dalam kelompok termasuk dengan cara melakukan bullying (Lestari, 2018). Kekompakan terjadi karena eratnya hubungan yang ada dalam kelompok, yang disebabkan oleh adanya kecocokan atau keinginan untuk mendapat manfaat dari kelompoknya (Febriyani \& Indrawati, 2016).

Iklim sekolah memengaruhi bullying secara signifikan dengan efek langsung sebesar $-0,17$, efek tidak langsung melalui sikap sebesar $-0,01$ dan total efek sebesar $-0,18$. Sejalan dengan penelitian Usman (2013) yang mendapatkan hasil iklim sekolah berpengaruh negatif signifikan terhadap perilaku bullying siswa, hal ini menunjukan semakin positif iklim sekolah maka semakin rendah perilaku bullying siswanya. Iklim sekolah positif berarti memberikan suasana yang positif secara fisik dan psikologis baik dari segi pembelajaran, interaksi dengan guru dan semua warga sekolah, serta norma yang jelas sehingga siswa tidak berminat untuk melakukan perilaku agresif (Rahmawati, 2016).
Media signifikan memengaruhi bullying dengan efek langsung sebesar 2,21 , efek tidak langsung melalui sikap sebesar $-0,07$ dan total efek 2,14. Hal ini sejalan dengan penelitian oleh Sufriani \& Sari (2017) yang mendapatkan hasil terdapat hubungan signifikan faktor media dengan perilaku bullying. Dalam penelitian ini juga menyebutkan terbiasa terpapar dengan tayangan televisi dan adegan kekerasan di gawai (gadget) membuat remaja menjadi stereotip dan lebih agresif. Penelitian Wilda (2016) mendapatkan bahwa didapatkan 56,9\% anak meniru adegan film yang ditontonnya. Sebanyak $64 \%$ meniru gerakan dan $43 \%$ meniru katakatanya.

Kelemahan dalam penelitian ini adalah peneliti tidak turun langsung ke lapangan untuk mengumpulkan data dikarenakan situasi pandemi Covid-19. Hal ini dapat memicu terjadinya bias informasi karena ada kemungkinan dijawab dengan bantuan orang lain (orang tua). Walaupun demikian, untuk meminimalisir bias, peneliti melakukan pendekatan dan berkomunikasi langsung dengan siswa melalui grup kelas sebelum dan selama pengisian kuesioner berlangsung. Selama proses pengisian kuesioner juga dibantu oleh masing-masing wali kelas yang ada di grup kelas untuk memastikan siswa menjawab sendiri.

\section{SIMPULAN}

Berdasarkan hasil penelitian, dapat disimpulkan bahwa prevalensi bullying responden secara umum sebanyak 232 (83,15\%) melakukan perilaku bullying kategori rendah. Bullying verbal menjadi jenis bullying yang paling sering dilakukan 
responden dengan kategori rendah $(71,68 \%)$ dan kategori tinggi (1,43\%). Jenis bullying psikologis dilakukan oleh responden dengan kategori rendah sebanyak 46,95\%, dan perilaku bullying fisik paling sedikit dilakukan oleh responden dengan kategori rendah (44,09\%). Faktor yang signifikan memengaruhi bullying adalah situasi keluarga, yaitu semakin positif situasi keluarga, semakin rendah kecenderungan perilaku bullying. Faktor kedua yang memengaruhi bullying yaitu konformitas teman sebaya. Semakin kuat konformitas teman sebaya, maka kecenderungan berperilaku bullying juga semakin tinggi. Iklim sekolah signifikan memengaruhi bullying, dimana semakin positif iklim sekolah maka tindakan bullying siswa cenderung rendah. Media signifikan memengaruhi bullying, semakin sering remaja melihat adegan bullying di media, kecenderungan berperilaku bullying juga akan meningkat. Faktor yang tidak signifikan memengaruhi perilaku bullying adalah pengetahuan, sikap remaja terkait bullying, konsep diri, dan stress akademik.

\section{SARAN}

Adapun saran yang dapat penulis sampaikan adalah bagi orang tua agar menjadi contoh yang baik bagi anak dan memberikan pemahaman tentang apa yang boleh dan tidak boleh dilakukan terkait perilaku bullying. Bagi pihak sekolah agar membuat tata tertib beserta sanksi yang tegas apabila melanggar tata tertib tersebut. Tata tertib juga harus disosialisasikan agar semua warga sekolah paham sehingga menciptakan suasana aman bagi semua warga sekolah. Bagi pemerintah khususnya KPAI agar menggalakan kampanye mengenai bullying dan kesehatan mental. Bagi Komisi Penyiaran Indonesia (KPI) agar tidak menayangkan hal-hal yang menunjukan perilaku bullying agar tidak ditiru oleh penonton. Bagi peneliti selanjutnya apabila ingin membuat penelitian agar melakukan metode kualitatif pada variabel sikap dan konsep diri agar mendapatkan informasi yang lebih mendalam tentang apa yang mendorong remaja melakukan perilaku bullying.

\section{UCAPAN TERIMA KASIH}

Terimakasih kepada Dinas Pendidikan, Kepemudaan dan Olahraga Pemerintah Kota Denpasar, serta Kepala Sekolah SMP Negeri dan SMP Swasta di Kota Denpasar yang telah membantu melancarkan penelitian dan membantu memudahkan penulis memeroleh data.

\section{DAFTAR PUSTAKA}

Ahmad, E. H. (2019). Cognitive-Behavioral Therapy Untuk Menangani Kemarahan Pelaku Bullying Di Sekolah. JBKI (Jurnal Bimbingan Konseling Indonesia), 4(1), 14-18.

Azeredo, C. M., Rinaldi, A. E. M., de Moraes, C. L., Levy, R. B., \& Menezes, P. R. (2015). School bullying: A systematic review of contextual-level risk factors in observational studies. Journal of Aggression and Violent Behavior, 22, 1-38.

Barseli, M., Ifdil, \& Nikmarijal. (2017). Konsep Stres Akademik Siswa. Jurnal Konseling Dan Pendidikan, 5(3), 143148. https://doi.org/10.29210/119800

Borualogo, I. S., \& Gumilang, E. (2019). 
Kasus Perundungan Anak di Jawa

Barat: Temuan Awal Children's Worlds Survey di Indonesia. Psympathic: Jurnal Ilmiah Psikologi, 6(1),

https://doi.org/10.15575/psy.v6i1.4439

Coloroso, B. (2007). Stop Bullying. Serambi Ilmu Pustaka.

Depkes, R. . (2009). Profil Kesehatan Indonesia. Depkes RI.

Dewi, C. K. (2015). Pengaruh Konformitas Teman Sebaya Terhadap Perilaku Bullying pada Siswa SMA Negeri 1 Depok Yogyakarta. Skripsi.Universitas Negeri Yogyakarta.

Febriyani, Y., \& Indrawati, E. (2016). Konformitas Teman Sebaya Dan Perilaku Bullying Pada Siswa Kelas XI IPS. Jurnal Empati, 5(1), 138-143.

Hasan, A. B. P. (2013). Efektivitas Pelatihan Anti-Bullying terhadap Pengetahuan Penanganan Kasus Bullying di Sekolah pada Guru-Guru TK Jakarta. Jurnal AL-Azhar Indonesia Seri Humaniora, 2(2), 81-88.

Hermalinda, Deswita, \& Oktarina, E. (2017). Hubungan Karakteristik Remaja Dengan Perilaku Bullying Pada Siswa SMP Di Kota Padang. Jurnal Keperawatan Soedirman, 12(1), 111.

Kholilah, M. (2012). Hubungan Tingkat Pengetahuan Remaja Tentang Bullying dengan Perilaku Bullying pada Siswa Kelas XI di SMA Semen Gresik. Skripsi.

Kundre, R., \& Rompas, S. (2018). Hubungan (Bullying) Dengan Kepercayaan Diri pada Remaja di SMP Negeri 10 Manado. E-Journal Keperawatan, 6(1), 1-6.

Lestari, W. O. (2018). Pengaruh Konsep
Diri dan Konformitas Terhadap Perilaku Perundungan. Jurnal Psikoborneo, 6(3), 681-690.

Leung, C. H., \& To, H. K. (2009). The Relationship Between Stress and Bullying Among Secondary School Students. Journal New Horizons in Education, 57(1), 33-42.

Marela, G., Wahab, A., Raymondalexas, C., \& Marchira, . (2017). Bullying Verbal Menyebabkan Depresi pada Remaja SMA di Kota Yogyakarta. BKM Journal of Community Medicine and Public Health, 33(1), 43-48.

Nadhifa, Y. (2018). Pengaruh Moral Disengagement dan Iklim Sekolah Terhadap Perilaku Bullying pada Pelajar SMA di Jakarta. Skripsi.UIN Syarif Hidayatullah Jakarta.

Nurhayanti, R., Novotasari, D., \& Natalia. (2013). Tipe Pola Asuh Orang Tua yang Berhubungan dengan Perilaku Bullying di SMA Kabupaten Semarang. Jurnal Keperawatan Jiwa, 1(1), 49-59.

Pouwels, Lansu, \& Cillessen. (2017). Adolescents' Explicit and Implicit Evaluations of Hypothetical and Actual Peers with Different Bullying Participant Roles. Journal of Experimental Child Psychology, 159, 219-241.

Putri, H. N., Nauli, F. A., \& Novayelinda, R. (2015). Faktor-Faktor yang Berhubungan dengan Perilaku Bullying pada Remaja. JOM, 2(2), 1149-1159.

Rahmawati, S. W. (2016). Peran Iklim Sekolah Terhadap Perundungan. Jurnal Psikologi, 43(2), 167-180.

Santrock, J. W. (2003). Adolescence 
Perkembangan Remaja. Jakarta:PT. Erlangga.

Sari, D. J., Ides, S. A., \& Anggraeini, L. D. (2017). Latar Belakang Remaja Melakukan Bullying di Sekolah Menengah Kejuruan (SMK). Jurnal Ners Dan Kebidanan Indonesia, 5(2), 149-156.

https://doi.org/10.21927/jnki.2017.5(2). 149-156

Schleicher, A. (2019). PISA 2018 Insights and Interpretations. In OECD Publishing.

https://www.oecd.org/pisa/PISA 2018 Insights and Interpretations FINAL PDF.pdf

Sufriani, \& Sari, E. P. (2017). Faktor Yang Mempengaruhi Bullying Pada Anak Usia Sekolah Di Sekolah Dasar Kecamatan Syiah Kuala Banda Aceh. Idea Nursing Journal, 8(3).

Sun, J. (2011). Educational Stress Scale for Adolescent: Development, Validity, and Reliability with Chinesse Students. Journal of Psychoeducational Asessment, 29(6).

Susanti, I. G., \& Wulanyani, N. M. S. (2019). Pengaruh Dukungan Sosial Teman Sebaya dan Kontrol Diri Terhadap Perundungan (Bullying ) pada Remaja Awal di Denpasar. Jurnal Psikologi Udayana, 6(1), 182-192.

Tamtomo, A. (2014). Hubungan Antara Stres Sekolah dan Dukungan Teman Sebaya Terhadap Perilaku Bullying pada Siswa. Tesis.Muhammadiyah Surakarta.

Tanlain, Y. E. (2017). Pemodelan FaktorFaktor Yang Mempengaruhi Perilaku
Bullying Siswa SMA " $X$ " Surabaya Dengan Metode Structural Equation Modeling. Skripsi.Institut Teknologi Sepuluh Nopember.

Trevi, \& Respati, W. S. (2012). Sikap Siswa Kelas X SMK Y Tangerang Terhadap Bullying. Jurnal Psikologi, 10(01).

Tumon, M. B. A. (2014). Studi Deskriptif Perilaku Bullying pada Remaja. Jurnal Ilmiah Mahasiswa Universitas Surabaya, 3(1), 1-17.

Usman, I. (2013). Kepribadian, Komunikasi, Kelompok Teman Sebaya, Iklim Sekolah Dan Perilaku Bullying. Jurnal Humanitas, 10(1), 4960.

Utami, A. N. (2019). Identifikasi FaktorFaktor Penyebab. Jurnal Pendidikan Guru Sekolah Dasar, 8, 795-806.

Wardani, L. K., \& Fajriansyah. (2017). Perilaku Bullying Mahasiswa Kesehatan. Journal Of Nursing Practice, 17-23.

Wilda, F. (2016). Faktor-Faktor Yang Berhubungan Dengan Perilaku Bullying Pada Siswa SMKN 1 Padang Tahun 2016. Tesis.Universitas Andalas.

Windasari, M. A. C. (2015). Prevalence School Bullying and Relation with Academic Achievements Among Junior High School Students. 1-18.

Yandri, H. (2014). Peran Guru BK/Konselor Dalam Pencegahan Tindakan Bullying Di Sekolah. Jurnal Pelangi, 7(1), 97-107. Zakiyah, E. Z., Humaedi, S., \& Santoso, M. B. (2017). Faktor Yang Mempengaruhi Remaja dalam Melakukan Bullying. Penelitian Dan PPM, 4(2), 129-389. 